\title{
Challenges in pulmonary fibrosis - 5: The NSIP/UIP debate
}

\author{
Roland du Bois, Talmadge E King Jr
}

Thorax 2007;62:1008-1012. doi: 10.1136/thx.2004.031039

Among the idiopathic interstitial pneumonias, the two entitiesidiopathic pulmonary fibrosis (IPF) characterised by the presence of the usual interstitial pneumonia pattern of histopathology (IPF/UIP) and non-specific interstitial pneumonia (NSIP; same nomenclature for the histopathological pattern and idiopathic disease)-have provoked considerable debate. IPF/ UIP and NSIP closely mimic each other clinically but NSIP has a far better outcome. However, it remains unclear if NSIP is a truly separate and distinct entity. The histopathological pattern of NSIP can be found in a wide variety of clinical and radiological contexts. This review addresses these and other uncertainties regarding NSIP and UIP.

See end of article for authors' affiliations

Correspondence to:

Professor Talmadge E King

Jr, Department of Medicine

U'CSF, 1001 Potrero

Avenue, Room $5 \mathrm{H} 22$

San Francisco, California

94110, USA; tking@

medsfgh.ucsf.edu

Received 12December 2005

Accepted 26 April 2006
I 2002 the American Thoracic Society (ATS) and European Respiratory Society (ERS) published a joint statement detailing a revised classification of the idiopathic interstitial pneumonias (IIPs). This statement was the product of several meetings of a multidisciplinary core panel and was reviewed by specialists in all disciplines across the respiratory field. The need for the classification had become clear-in the absence of a consistent nomenclature there was widespread confusion and conflicting data in the literature. The goal was to provide an integrated clinical, radiological and pathological classification that all agreed would not be the final word but would provide a template for defining disease in order to inform approaches to immunogenetic and pathogenetic study and new targeted therapeutic trials.

The terminology applied to the IIPs had been confusing. In the past, idiopathic pulmonary fibrosis (IPF) was used in the USA and cryptogenic fibrosing alveolitis was used in the UK, and both referred to a collection of entities that included a range of histological patterns. The ATS/ERS consensus panel revised the classification schema and emphasised the importance of an integrated clinical, radiological and pathological approach to the diagnosis of IIP. In addition, they concluded that the IIPs comprised a number of clinicopathological entities which were sufficiently different from one another to be designated as separate diseases. Figure 1 illustrates the broad classification and table 1 sets out the nomenclature of the histological patterns against the clinical/radiologi$\mathrm{cal} /$ pathological diagnoses.

Of these disorders, the two entities that have provoked most discussion and debate are idiopathic pulmonary fibrosis (IPF; as currently defined with a usual interstitial pneumonia (UIP) pattern of pathology) and non-specific interstitial pneumonia (NSIP). There are two key reasons for this. First, IPF as now defined carries a worse prognosis than before; NSIP is its closest mimic but with a better outcome and therefore it seems extremely logical to dissect out these two entities in the patient's best interests. Second, it has become clear that the histopathological pattern of NSIP can be found in a wide variety of clinical and radiological contexts. ${ }^{2}$ This differentiation is more than semantic, having important implications on patient outcome and choice of treatment. With this background, this review sets out to address some of the ongoing uncertainties regarding NSIP and UIP, tacitly recognising that the published IIP classification is by no means the final word but rather the basis for future refinement of definition.

\section{IDIOPATHIC PULMONARY FIBROSIS (IPF)}

Classically, IPF/UIP is a disease of unknown cause or association characterised by slowly progressive breathlessness and crackles on auscultation of the chest in individuals aged $>50$ years. The major and minor diagnostic criteria are shown in box 1 . The clinical course is variable, but the long-term survival is poor with only $20-30 \%$ survival 5 years after the time of diagnosis.

Key features on high-resolution CT (HRCT) scanning are a peripheral distribution of disease predominantly at the bases consisting of a reticular pattern with honeycombing. There is little or no ground-glass opacification, nodules or significant hilar or mediastinal lymphadenopathy (fig 2).

Key histological features of the UIP pattern are patchy geographical distribution and heterogeneity in terms of the stage of pathology in different regions of the biopsy specimen (table 2 ). There is honeycombing, relatively little cellular inflammation and regions of proliferating myofibroblasts known as fibroblastic foci. Areas of normal lung should be present, in the absence of which the histopathological pattern may be difficult to define. In the past it was commonly stated that the UIP pattern could be found in collagen vascular disease, drug toxicity, asbestosis, chronic hypersensitivity pneumonitis and rare syndromes such as familial IPF and the Hermansky-Pudlak syndrome. However, using the more strict histopathological criteria, as defined here, has resulted in much less overlap. Commonly, the only features that raise the question of whether or not the UIP pattern is present in many of these situations is the presence of dense end-stage fibrotic changes without the presence of any other distinguishing

Abbreviations: IIP, idiopathic interstitial pneumonia; IPF, idiopathic pulmonary fibrosis; NSIP, non-specific interstitia pneumonia; UIP, usual interstitial pneumonia 


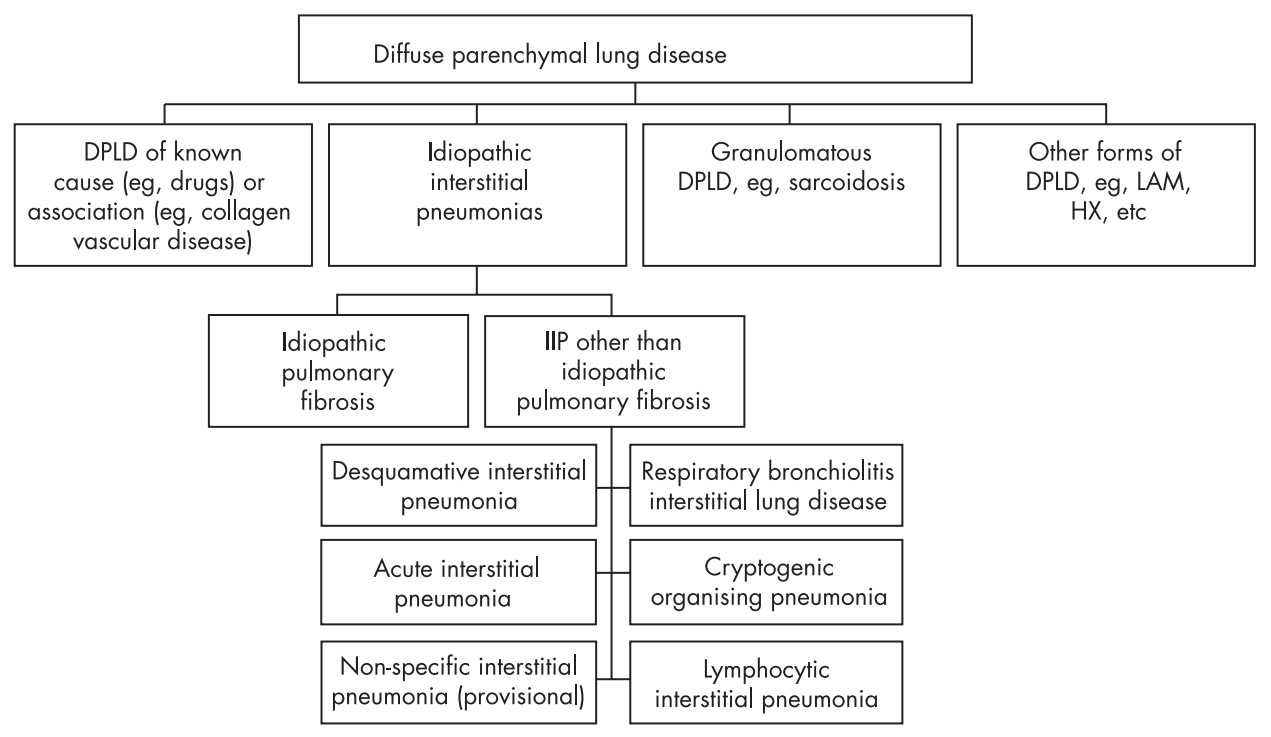

Figure 1 Classification of diffuse lung diseases.

features, especially fibroblastic foci. More importantly, these entities often have other features that allow recognition that the pattern is not UIP alone (such as asbestos bodies, ill-formed granulomas, marked interstitial chronic inflammation, prominent lymphoid follicles or organising pneumonia).

\section{NON-SPECIFIC INTERSTITIAL PNEUMONIA (NSIP)}

The clinical presentation of fibrotic NSIP (cellular NSIP is very uncommon) is similar to IPF, although the patients tend to be women and younger in age. ${ }^{3}$ Most cases with the histopathological pattern of NSIP are of unknown aetiology. Many cases with this histopathological pattern, however, occur in the context of an underlying disorder such as a connective tissue disease, drug-induced interstitial lung disease or chronic hypersensitivity pneumonitis. ${ }^{2}$ The majority of patients with idiopathic NSIP have a good prognosis with a 5-year mortality rate estimated at $<15 \%$.

Key features on HRCT scans are bilateral symmetrical predominantly basal ground-glass opacities, often with traction bronchiectasis or occasionally small areas of air space consolidation and lower lobe volume loss (fig 3). ${ }^{4}$

Table 1 Histological and clinical classification of idiopathic interstitial pneumonias*

\begin{tabular}{ll}
\hline Histological patterns & $\begin{array}{l}\text { Clinical/radiological/pathological } \\
\text { diagnosis }\end{array}$ \\
\hline Usual interstitial pneumonia & $\begin{array}{l}\text { Idiopathic pulmonary fibrosis/cryptogenic } \\
\text { fibrosing alveolitis }\end{array}$ \\
$\begin{array}{l}\text { Non-specific interstitial } \\
\text { pneumonia }\end{array}$ & $\begin{array}{l}\text { Non-specific interstitial pneumonia } \\
\text { (provisional)t }\end{array}$ \\
$\begin{array}{l}\text { Organising pneumonia } \\
\text { Diffuse alveolar damage } \\
\text { Respiratory bronchiolitis }\end{array}$ & $\begin{array}{l}\text { Acute interstitial pneumonia } \\
\text { Respiratory bronchiolitis interstitial lung } \\
\text { disease }\end{array}$ \\
$\begin{array}{l}\text { Desquamative interstitial } \\
\text { Desquamative interstitial pneumonia } \\
\text { pymphoid interstitial } \\
\text { pneumonia }\end{array}$ & Lymphoid interstitial pneumonia \\
\hline
\end{tabular}

*Unclassifiable interstitial pneumonia: some cases are unclassifiable for a variety of reasons.

†A heterogeneous group with poorly characterised clinical and radiological features that needs further study.

$\ddagger$ Cryptogenic organising pneumonia is the preferred term but it is synonymous with idiopathic bronchiolitis obliterans organising pneumonia. Reproduced with permission from the American Thoracic Society/European Respiratory Society.'
The key histopathological features of NSIP are the uniformity of interstitial involvement across the biopsy section and this may be predominantly cellular or fibrosing (table 2). There is less temporal and spatial heterogeneity than in UIP and little honeycombing. The cellular variant is uncommon, so this review will focus on the more common variant-fibrosing NSIP - that is often misdiagnosed as IPF/UIP. ${ }^{5}$

\section{CAN NSIP BE DISTINGUISHED FROM UIP USING CLINICAL AND IMAGING FEATURES?}

Several studies have now shown that the accuracy of diagnosis of IPF is high when the degree of confidence in the diagnosis is

\section{Box 1 Defining criteria for idiopathic pulmonary} fibrosis

\section{Major criteria}

- Exclusion of other known causes of interstitial lung disease such as certain drug toxicities, environmental exposures and connective tissue diseases.

- Abnormal pulmonary function studies that include evidence of restriction (reduced vital capacity often with an increased forced expiratory volume in $1 \mathrm{~s} /$ forced vital capacity ratio) and impaired gas exchange (increased alveolar-arterial oxygen tension difference with rest or exercise or decreased carbon monoxide transfer factor).

- Bibasilar reticular abnormalities with minimal groundglass opacities on high-resolution CT scans.

- Transbronchial lung biopsy or bronchoalveolar lavage fluid showing no features to support an alternative diagnosis.

\section{Minor criteria}

- Age $>50$ years.

- Insidious onset of otherwise unexplained dyspnoea on exertion.

- Duration of illness $\geqslant 3$ months.

- Bibasilar inspiratory crackles (dry or "Velcro" type in quality).

Reproduced with permission from American Thoracic Society. ${ }^{28}$ 


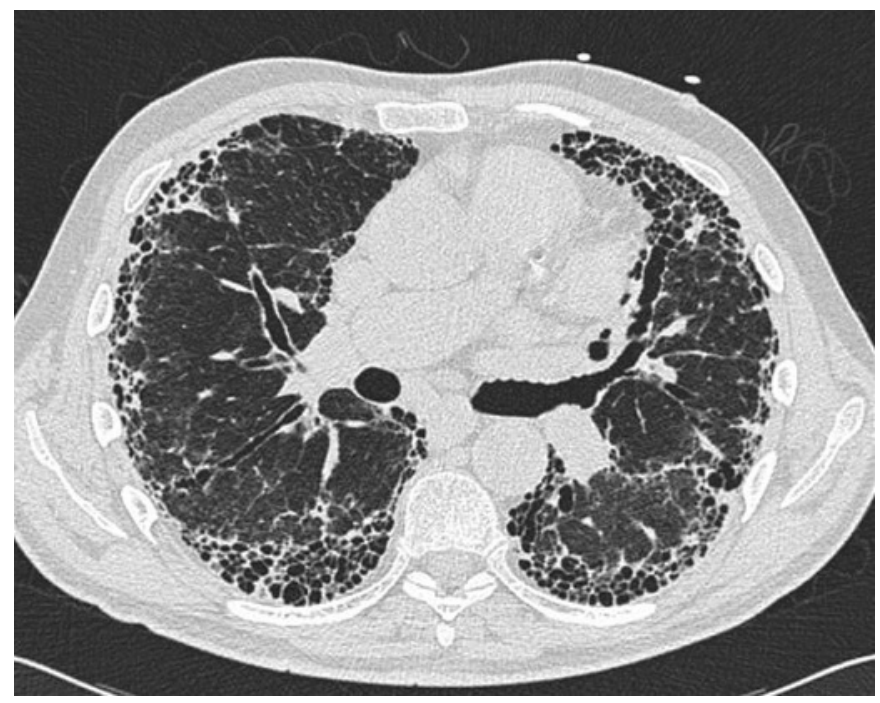

Figure 2 Typical CT scan from a patient with idiopathic pulmonary fibrosis. Note the peripheral distribution of disease, the coarse reticular pattern with honeycombing and the absence of much ground-glass change.

high. ${ }^{6-8}$ In practice, this means that the clinical and radiological features together with the absence of an alternative diagnosis from bronchoalveolar lavage or transbronchial biopsy are entirely consistent with "no unusual features". However, in a cohort of patients with IPF, the diagnosis would be missed in $30-40 \%$ using indices that do not include a biopsy. In the same vein, a diagnosis of NSIP without a biopsy is highly inaccurate with roughly $50 \%$ being missed. Common conditions that may be confused with idiopathic NSIP include hypersensitivity pneumonitis, lymphocytic interstitial pneumonia, respiratory bronchiolitis associated interstitial lung disease and desquamative interstitial pneumonia. As a general rule, a suspected diagnosis of NSIP will always require a surgical biopsy whereas a confident diagnosis of IPF without a biopsy is usually correct. Bronchoalveolar lavage is unhelpful in distinguishing NSIP from IPF when the clinical features mimic IPF (especially with no features on CT scanning that resemble hypersensitivity pneumonitis or organising pneumonia). It may be argued that an

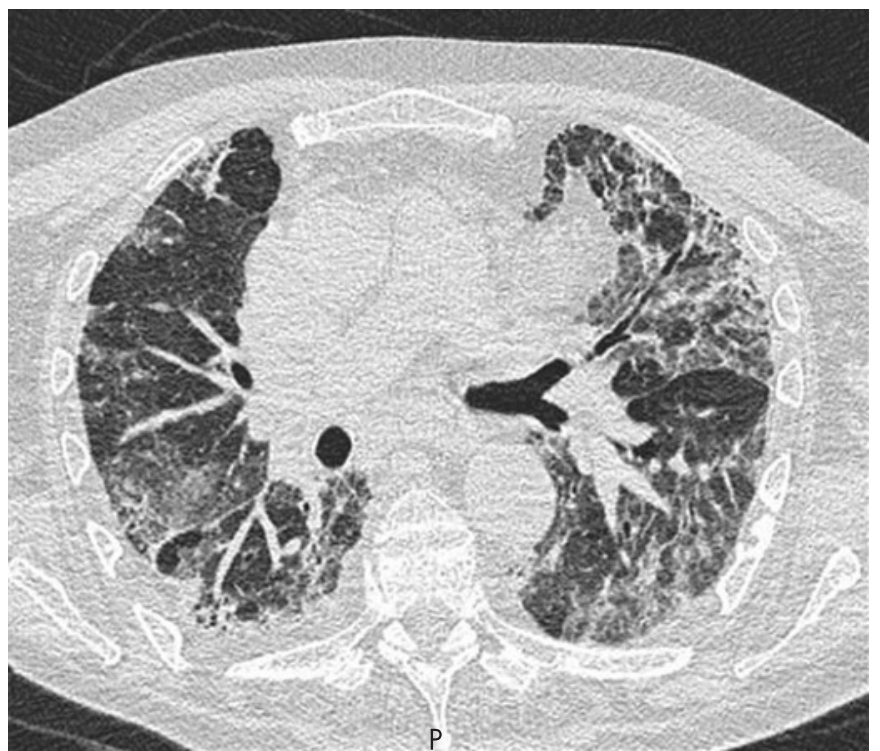

Figure 3 Typical CT scan from a patient with non-specific interstitial pneumonia. Note the less peripheral distribution of disease than in idiopathic pulmonary fibrosis and the widespread ground-glass change, but with clear evidence of traction of the airways indicating that at least some, but not necessarily all, of this ground change is due to fine fibrosis.

empirical 3-month trial of corticosteroids is a less intrusive approach to management without resorting to a surgical biopsy to make a more precise diagnosis. This presumes that drug treatment is the only issue. However, discussions about the pros and cons of treatment and the likely outcome are important components of management that are highly relevant to an individual patient and require as much data as possible. Furthermore, corticosteroids are now rarely the first-line treatment of choice and often leave the patient with no improvement and significant side effects. This empirical approach is not recommended.

\section{WHAT IS THE PURPOSE OF PERFORMING A SURGICAL BIOPSY?}

It is commonly argued that surgical biopsy information has no impact on treatment options. As the therapeutic regimens

Table 2 Distinguishing clinical features of idiopathic pulmonary fibrosis (IPF) and non-specific interstitial pneumonia (NSIP)

\begin{tabular}{|c|c|c|}
\hline $\begin{array}{l}\text { Clinical/radiographic/ } \\
\text { pathological features }\end{array}$ & IPF & NSIP \\
\hline $\begin{array}{l}\text { Duration of illness } \\
\text { Frequency of diagnosis } \\
\text { Chest radiograph }\end{array}$ & $\begin{array}{l}\text { Chronic (>12 months) } \\
47-64 \% \\
\text { Bilateral reticular opacities in lower zones; volume loss; } \pm \\
\text { honeycombing }\end{array}$ & $\begin{array}{l}\text { Subacute to chronic (months to years) } \\
14-36 \% \\
\text { Bilateral hazy and reticular opacity }\end{array}$ \\
\hline HRCT & $\begin{array}{l}\text { Peripheral, subpleural, basal predominance } \\
\text { Reticular opacities } \\
\text { Honeycombing } \\
\text { Traction bronchiectasis } \\
\text { Architectural distortion. } \\
\text { Focal ground-glass }\end{array}$ & $\begin{array}{l}\text { Peripheral, subpleural, basal, symmetrical } \\
\text { Ground-glass attenuation } \\
\text { Consolidation } \\
\text { Lower lobe volume loss }\end{array}$ \\
\hline Key histological features & $\begin{array}{l}\text { Usual interstitial pneumonia pattern } \\
\text { Dense fibrosis causing remodeling of lung architecture with } \\
\text { frequent "honeycomb" fibrosis } \\
\text { Fibroblastic foci typically scattered at the edges of dense scars } \\
\text { Patchy lung involvement } \\
\text { Frequent subpleural and paraseptal distribution }\end{array}$ & $\begin{array}{l}\text { NSIP pattern } \\
\text { Cellular pattern } \\
\text { Mild to moderate interstitial chronic inflammation } \\
\text { Type II pneumocyte hyperplasia in areas of inflammation } \\
\text { Fibrosing pattern } \\
\text { Dense or loose interstitial fibrosis lacking the temporal } \\
\text { heterogeneity pattern and/or patchy features of UIP } \\
\text { Lung architecture may appear lost on examination of H\&E stained } \\
\text { sections but relatively preserved with elastic stains } \\
\text { Interstitial chronic inflammation (mild or moderate) }\end{array}$ \\
\hline $\begin{array}{l}\text { Treatment } \\
\text { Prognosis }\end{array}$ & $\begin{array}{l}\text { Poor response to any treatment } \\
50-70 \% \text { mortality in } 5 \text { years }\end{array}$ & $\begin{array}{l}\text { Corticosteroid responsiveness } \\
\text { Unclear; }<15 \% \text { mortality in } 5 \text { years }\end{array}$ \\
\hline
\end{tabular}

Adapted from American Thoracic Society/European Respiraratory Society. 
Table 3 Histopathological subsets in connective tissue disease

\begin{tabular}{lllll}
\hline $\begin{array}{l}\text { Pathological } \\
\text { feature }\end{array}$ & $\begin{array}{l}\text { Total } \\
(\mathbf{n}=177)\end{array}$ & $\begin{array}{l}\text { Systemic } \\
\text { sclerosis* } \\
(\mathbf{n}=102)\end{array}$ & $\begin{array}{l}\text { Rheumatoid } \\
\text { arthritist } \\
(\mathbf{n}=\mathbf{4 0})\end{array}$ & $\begin{array}{l}\text { Polymyositis- } \\
\text { dermatomyositis } \\
(\mathbf{n}=51)\end{array}$ \\
\hline NSIP & $146(82 \%)$ & 83 & 23 & 46 \\
UIP & $31(18 \%)$ & 19 & 17 & 5 \\
\hline NSIP, non-specific interstitial pneumonia; UIP, usual interstitial pneumonia. & \\
"Data from references 13-16. \\
tData from references 16, 17, 29. \\
tData from references 14, 17-19. \\
Adapted from King.
\end{tabular}

currently used are limited, there is an element of truth in this statement. There are, however, a number of compelling reasons to rebut this view. First, knowing at presentation that an individual has NSIP and not UIP allows the clinician to convey a more optimistic prognosis; many studies have now shown that NSIP has a better survival than UIP. Second, a short course of higher dose corticosteroids may have a significantly better efficacy/side effect profile in NSIP than in UIP where the emergence of side effects with no sustained clinical improvement together results in worse global symptomatology. Third, even with alternative (immunosuppression) first-line treatment approaches, the balance of likely good versus adverse effects can be articulated with more precision to an individual patient rather than quoting average survival and side effect data. Fourth, trials of new treatment are being undertaken on individuals with well defined disease in order to maximise the likely response to the novel agent; to have a mixed population only confuses the interpretation. There is, however, a caveat. If disease is well advanced, the outcome appears to be no different between UIP and NSIP. In this regard, Latsi et al showed that if the carbon monoxide transfer factor was $<35 \%$ predicted, there was a similarity in survival between the two populations. ${ }^{9}$

\section{WHAT IF THE BIOPSIES ARE DISCORDANT WITH EACH OTHER OR WITH HRCT SCANS?}

The finding of an HRCT scan that does not fulfil the classic features that would predict a UIP pattern of histopathology does not exclude the possibility that the surgical biopsy would reveal UIP. What is the significance of this finding? In one of a series of studies in IPF and NSIP, Flaherty et al ${ }^{10}$ showed that the discordance between HRCT and biopsy findings had implications for the prognosis. HRCT/biopsy concordance for NSIP carried a much better prognosis than HRCT/biopsy concordance for IPF, but the NSIP HRCT/UIP biopsy group had survival that was intermediate. In other words, while a UIP biopsy had a clear adverse effect on outcome, it was less severe than in classic UIP. Whether this means that there is heterogeneity in the IPF population or whether this is a stage of disease (ie, the HRCT scan would ultimately progress to a more convincing UIP pattern) is uncertain. Similar data emerged from another study from the Michigan group in which multiple biopsies from the same patient were compared in a series of 109 patients. ${ }^{11}$ If the biopsies were consistently NSIP, survival was better than if there was discordance between biopsies (UIP/NSIP at different sites); the survival in the discordant group appeared better at 3 years but not at 5 years. It was concluded that the discordant group had no survival advantage over the UIP concordant group_-UIP "trumps" NSIP_but it must be noted that the convergence of the survival curves between years 3 and 5 was caused by the deaths of only four patients so interpretation at this time point may have been confounded by small numbers. In any event, the finding of even a single biopsy with a UIP pattern must be considered a bad prognostic index.

\section{DOES NSIP EVOLVE INTO UIP?}

We do not know the answer to this with certainty, but probably not. No reports have documented the progression of NSIP to UIP (or vice versa). Katzenstein and co-workers suggested that the initial injury in UIP could itself cause secondary inflammation and fibrosis that resemble NSIP, thus explaining the finding of NSIP-like areas in UIP. ${ }^{12}$ In support of this hypothesis, they showed that areas resembling NSIP were present in the majority of UIP cases in both biopsy and explant specimens and were extensive in some. ${ }^{12}$ In addition, no explant that showed UIP was found to show NSIP in the preceding biopsy, and the one patient with NSIP who underwent transplantation had a biopsy specimen and explant that showed similar features. In the authors' view, the observation that a cluster of patients with apparently NSIP dies at a rate that matches that of IPF is insufficient to draw this conclusion. Certainly, we must not make the "lumping" error of the past when, for example, desquamative interstitial pneumonia was long thought to be part of the same disease spectrum as IPF.

\section{IS NSIP IN RHEUMATOLOGICAL DISEASE THE SAME AS IDIOPATHIC NSIP?}

There have been a number of recent reports that have confirmed that the predominant pattern of histopathology in most of the rheumatological diseases is NSIP, especially in systemic sclerosis, rheumatoid arthritis and dermatomyositis/ polymyositis (table 3). ${ }^{13-19}$ Possible exceptions to this include the lymphocytic interstitial pneumonia that can be seen particularly in Sjögren's syndrome, and some patients with rheumatoid arthritis or the organising pneumonia pattern that can be characteristic of dermatomyositis/polymyositis. A few cases with rheumatological disease will show the pattern of UIP. However, these cases do not behave like patients with IPFthat is, they have atypical clinical, radiographic or histopathological features and survival is better than in IPF. ${ }^{15} 162021$

Should this therefore be regarded as being the same "disease" as idiopathic NSIP? There are many lines of evidence that suggest that we should be cautious in this regard. First, in systemic sclerosis the behaviour of the disease is much less aggressive than in idiopathic disease, even allowing for matching of amount and severity of disease at presentation. ${ }^{1}{ }^{21}$ Second, there are often coexistent patterns of disease such as bronchiectasis or even occasionally granulomas in the NSIP associated with rheumatological disease. ${ }^{22}$ Third, there is often a more exuberant nodular follicular hyperplasia in the NSIP seen in rheumatological diseases. ${ }^{23}$

Interestingly, preliminary data from the ATS/ERS NSIP Workshop Committee showed that, unlike patients with IPF, most of the patients with idiopathic NSIP were women, never smokers and with serological abnormalities (antinuclear antibodies and rheumatoid factor) in the absence of a defined connective tissue disease. ${ }^{3}$ This raises the possibility that some cases of idiopathic NSIP represent an ill-defined or early stage of a connective tissue disease. In a recent report, most patients 
diagnosed with idiopathic NSIP met the case definition of undifferentiated connective tissue disease, a newly described distinct entity. ${ }^{24}$

Given that the background of the rheumatological diseases is systemic with the presence of hallmark autoantibodies, it is the authors' view that these entities cannot be lumped together and that the common histopathological pattern of disease may well have arisen by disparate pathogenetic mechanisms with implications for different approaches to trials of treatment including novel agents.

\section{DOES IT REALLY MATTER THAT WE DISTINGUISH UIP FROM NSIP?}

The importance of differentiating NSIP from IPF lies in the management of the individual patient. It is recognised that there are limited treatment options for either of these diseases, but management extends beyond prescription of medication; discussions of likely outcome and pace of change are of fundamental importance. It is known from numerous series that patients with IPF generally do much worse than those with NSIP. This favours continuing to keep the entities.

One of the striking-and perhaps somewhat surprisingbenefits of the introduction of the classification that has allowed the teasing out of NSIP and UIP has been the enhanced involvement of the pharmaceutical industry in a number of trials of novel treatment. ${ }^{25-27}$ While only the IFIGENIA (Idiopathic Pulmonary Fibrosis International Group Exploring $\mathrm{N}$-Acetylcysteine I Annual) trial of acetylcysteine, given as addon therapy to prednisolone and azathioprine, met its primary endpoint of slowing the pace of change of physiological indices, the studies of interferon gamma, pirfenidone, bosentan and etanercept have all produced sufficiently encouraging data that further studies of these agents are either already underway or in design. Furthermore, other pharmaceutical companies have a number of agents either in development or in phase 1 trials, so the longer term outlook for novel approaches is good. Importantly, these studies have all targeted IPF; without a clear definition of IPF, this would not have been possible. The same will apply to future trials of the other idiopathic interstitial pneumonias of which NSIP is the prime target. The 2002 ATS/ ERS classification was never meant to be the final word and, as outlined in the document, there were many "gray" areas. However, the statement has provided the framework for studies of pathogenesis, clinical features and outcome and the basis for novel therapeutic intervention. The conclusion from the debate should therefore be clear; making the distinction between idiopathic UIP (IPF) and NSIP has important implications for how we talk to our patients about their lung disease now, and how we might advise them about novel studies in the future.

\section{Authors' affiliations}

R du Bois, Interstitial Lung Disease Unit, Department of Occupational and Environmental Medicine, National Heart and Lung Institute, Imperial College of Science, Technology and Medicine, London, UK

T E King Jr, Department of Medicine, University of California, San Francisco, California, USA

Competing interests: None.

\section{REFERENCES}

1 American Thoracic Society/European Respiratory Society. International multidisciplinary consensus classification of the idiopathic interstitial pneumonias. Am J Respir Crit Care Med 2002;165:277-304.
2 Katzenstein AL, Fiorelli RF. Nonspecific interstitial pneumonia/fibrosis. Histologic features and clinical significance. Am J Surg Pathol 1994;18:136-47.

3 Travis WD, King TE Jr, Hunninghake G, et al. American Thoracic Society Workshop on Idiopathic Nonspecific Interstitial Pneumonia (NSIP). American Thoracic Society International Conference; 18 May 2003, Seattle, Washington.

4 Lynch DA, Travis WD, Muller NL, et al. Idiopathic interstitial pneumonias: CT features. Radiology 2005;236:10-21.

5 Nicholson AG, Colby TV, du Bois RM, et al. The prognostic significance of the histologic pattern of interstitial pneumonia in patients presenting with the clinical entity of cryptogenic fibrosing alveolitis. Am J Respir Crit Care Med 2000;162:2213-7.

6 Hunninghake G, Zimmerman MB, Schwartz DA, et al. Utility of lung biopsy for the diagnosis of idiopathic pulmonary fibrosis. Am J Respir Crit Care Med 2001;164:193-6.

7 Raghu G, Mageto YN, Lockhart D, et al. The accuracy of the clinical diagnosis of new-onset idiopathic pulmonary fibrosis and other interstitial lung disease: a prospective study. Chest 1999;116:1168-74.

8 Flaherty KR, King TE Jr, Raghu G, et al. Idiopathic interstitial pneumonia: what is the effect of a multidisciplinary approach to diagnosis? Am J Respir Crit Care Med 2004; 170:904-10

9 Latsi PI, du Bois RM, Nicholson AG, et al. Fibrotic idiopathic interstitial pneumonia; the prognostic value of longitudinal lung function trends. Am J Respir Crit Care Med 2003;168:531-7.

10 Flaherty KR, Thwaite EL, Kazerooni EA, et al. Radiological versus histological diagnosis in UIP and NSIP: survival implications. Thorax 2003:58:143-8.

11 Flaherty KR, Travis WD, Colby TV, et al. Histopathologic variability in usual and nonspecific interstitial pneumonias. Am J Respir Crit Care Med $2001 ; 164: 1722-7$.

12 Katzenstein AL, Zisman DA, Litzky LA, et al. Usual interstitial pneumonia: histologic study of biopsy and explant specimens. Am J Surg Pathol 2002;26:1567-77.

13 Fujita J, Yoshinouchi T, Ohtsuki Y, et al. Non-specific interstitial pneumonia as pulmonary involvement of systemic sclerosis. Ann Rheum Dis 2001;60:281-3.

14 Kim DS, Yoo B, Lee JS, et al. The major histopathologic pattern of pulmonary fibrosis in scleroderma is nonspecific interstitial pneumonia. Sarcoidosis Vasc Diffuse Lung Dis 2002;19:121-7.

15 Bouros D, Wells AU, Nicholson AG, et al. Histopathologic subsets of fibrosing alveolitis in patients with systemic sclerosis and their relationship to outcome. Am J Respir Crit Care Med 2002;165:1581-6.

16 Nakamura Y, Chida K, Suda T, et al. Nonspecific interstitial pneumonia in collagen vascular diseases: comparison of the clinical characteristics and prognostic significance with usual interstitial pneumonia. Sarcoidosis Vasc Diffuse Lung Dis 2003;20:235-41.

17 Tansey D, Wells AU, Colby TV, et al. Variations in histological patterns of interstitial pneumonia between connective tissue disorders and their relationship to prognosis. Histopathology 2004;44:585-96.

18 Douglas WW, Tazelaar HD, Hartman TE, et al. Polymyositis-dermatomyositisassociated interstitial lung disease. Am J Respir Crit Care Med $2001 ; 164: 1182-5$.

19 Cottin V, Thivolet-Bejui F, Reynaud-Gaubert M, et al. Interstitial lung disease in amyopathic dermatomyositis, dermatomyositis and polymyositis. Eur Respir J 2003;22:245-50.

20 King TE Jr. Clinical advances in the diagnosis and therapy of the interstitial lung diseases. Am J Respir Crit Care Med 2005;172:268-79.

21 Wells AU, Cullinan P, Hansell DM, et al. Fibrosing alveolitis associated with systemic sclerosis has a better prognosis than lone cryptogenic fibrosing alveolitis. Am J Respir Crit Care Med 1994; 149:1583-90.

22 Cortet B, Flipo RM, Remy-Jardin M, et al. Use of high resolution computed tomography of the lungs in patients with rheumatoid arthritis. Ann Rheum Dis 1995;54:815-9

23 Tansey D, Wells AU, Colby TV, et al. Variations in histological patterns of interstitial pneumonia between connective tissue disorders and their relationship to prognosis. Histopathology 2004;44:585-96.

24 Kinder BW, Collard HR, Koth L, et al. Idiopathic NSIP: lung manifestation of undifferentiated connective tissue disease? Am J Respir Crit Care Med 2007 Epub ahead of print 7 June 2007.

25 Azuma A, Nukiwa T, Tsuboi E, et al. Double-blind, placebo-controlled trial of pirfenidone in patients with idiopathic pulmonary fibrosis. Am J Respir Crit Care Med 2005;171:1040-7.

26 Raghu G, Brown KK, Bradford WZ, et al. A placebo-controlled trial of interferon gamma-1b in patients with idiopathic pulmonary fibrosis. N Engl J Med 2004;350:125-33.

27 Demedts $M$, Behr J, Buhl R, et al. High-dose acetylcysteine in idiopathic pulmonary fibrosis. N Engl J Med 2005;353:2229-42.

28 American Thoracic Society. Idiopathic pulmonary fibrosis: diagnosis and treatment. International consensus statement. American Thoracic Society (ATS) and European Respiratory Society (ERS). Am J Respir Crit Care Med 2000;161:646-64.

29 Lee H-K, Kim DS, Yoo B, et al. Histopathologic pattern and clinical features of rheumatoid arthritis-associated interstitial lung disease. Chest 2005; 127:2019-27. 